\title{
Urban Guided Transport MANAgement Cyber SECURITY
}

\author{
Jan Prochazka, Petr Novobisky, Dana Prochazkova, Miroslav Rusko, Vojtech Kollar, \\ Vojtech Ferencz, Jan Ilko, Milan Majernik \& Stefan Majernik
}
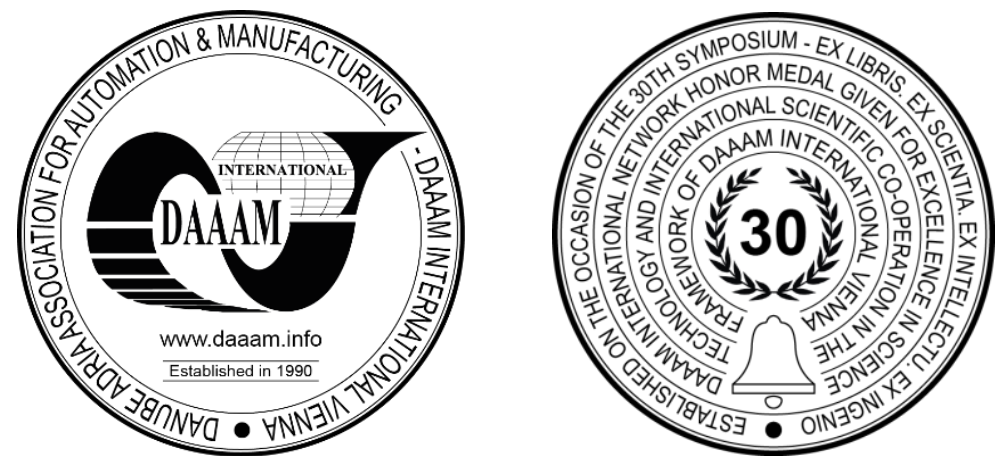

This Publication has to be referred as: Prochazka, J[an]; Novobilsky, P[etr]; Prochazkova, D[ana]; Rusko, M[iroslav]; Kollar, V[ojtech] \& Ferencz, V[ojtech] (2020). Urban Guided Transport Management Cyber Security, Proceedings of the 31st DAAAM International Symposium, pp.0376-0383, B. Katalinic (Ed.), Published by DAAAM International, ISBN 978-3-902734-29-7, ISSN 1726-9679, Vienna, Austria

DOI: $10.2507 / 31$ st.daaam.proceedings.052

\begin{abstract}
The Urban guided transport management cyber security is very important for human security and economic development of the Praha capital. The Urban guided transport management system (UGTMS) as subway, transports from several hundreds of thousands to million passengers per day. Intensity and irreplaceability of transport make from these subways the critical infrastructures of cities, regions or countries. Modern transport critical infrastructures contain in addition to physical and social parts also cyber control systems and they are marked as cyber physical systems (CPS). The CPSs are characterized by safety-critical nature, complexity, connectivity, and open technology. The CPS complexity, openness and dynamics form a large attack surface that may lead to failures and irreparable damage. Multiple Independent Levels of Security (MILS) can meet the high system security requirements. The MILS is a high-assurance security architecture based on the concepts of separation and controlled information flow. The article discusses the possibilities of using the MILS platform in the data communication subsystem, which connects the individual UGTMS subsystems (Wayside subsystem, On-board subsystem and operation control subsystem). The communication system should guarantee transmission parameters and do not affect security level of the respective subsystems, accordingly.
\end{abstract}

Keywords: Human security; Transport; Management; Cyber physical systems; Critical infrastructures.

\section{Introduction}

The critical infrastructure protection has become an essential part of advanced human systems security strategies [17], [21]. Critical infrastructures are often formed by extensive networks of physical elements (either point or line types), their management system, human factor, technical standards, relevant legislation and management strategy as well [6], [16], [19]. It is necessary to take care of the security barriers for all mentioned types of elements (hard elements, soft elements, human factor and documents) in order to ensure the protection of the critical infrastructure [13], [20]. Physical protection is not enough [22]. The protection of infrastructure management systems is mostly linked to a single environment, through which managements are implemented for all infrastructures, the communication infrastructure [12], [14]. The protected system can be divided into three parts in terms of elements protection. We have a network of physical components distributed over an extensive territory that needs to be coordinated. 
The physical components may be stationary (lights, switches) or mobile (train sets). The second part is dispatch management. The dispatch management consists of a human factor and an information system. The physical components and the dispatch management are connected through third part, i.e. the communication system. The communication takes place through the cyber space and with physical component form cyber physical systems (CPS). The communication system needs to reliable secure available information flow at maintainable intensity, which will be also safe, RAMS (EN 50126-1 1999) [5].

The article will exclusively address the security of interfaces between the communication system and the internal cyber environment of the critical infrastructure furthermore [4]. The solution with the least risk would be built up its own isolated data transmission system from the cyber security of the communication system point of view. Such a solution would be safe and reliable, yet unavailable and unmaintainable. The physical extensiveness of infrastructures forms a large attack surface in physical space and it has high demands on the communication system [11]. The public communication infrastructure is also used for communication, and therefore, the vastness, openness and dynamism of the public network leads to a large attack surface, this time in cyberspace, however with possible impacts in cyberspace and physical space as well [18], the Urban Guided Transport Management System (UGTMS) is an example of such infrastructure. UGTMS is described in the second chapter.

The security of the gates, which the information flow use for overcoming the interfaces between systems, can be ensured in the usual ways - access keys, passwords, firewalls, and so on. However, the regular gateway security techniques may not be sufficient in the case of critical infrastructures. Therefore, a system with multiple independent levels of security (MILS) is appropriate to use [15]. System with the MILS principle guarantee that overcoming of one barrier does not make an attacker any easier to access other barriers. The MILS principles are described in Chapter 3. Chapter 4 deals with aspects of application of MILS principles at the Prague metro/subway as representatives of UGTMS.

\section{The Urban Guided Transport Management}

According to present knowledge and experience, three aspects of the UGTMS are important: system management levels; system architecture; and cyber-attacks at cyber-physical systems.

\subsection{System Management levels}

The structure of UGTMS can be divided according several various planes. One is the management plane where we distinguish three elemental levels, Fig 1. The "Operation planning" is ensured at the highest level, both long-term (strategic management) and short-term (tactical management). Only the level of politic management lies above the operation planning. The policy level for UGTMS is given by standard [9]. The lower two stages of the pyramid at Fig. 1, are "Operation management and supervision" (Operational Management) and "Train operation" (Technical Management). Operation management and train operation lay at lower level of management pyramid than operation planning at offices; however, they are more critical from the point of view of cyber security. Operation control centre and decentralized control of trains and waysides are an example of CPS. It is also necessary to ensure proper maintenance of the whole system in addition to management levels of operation. Maintenance pervades through the whole pyramid, from operation planning at top to train management at bottom.

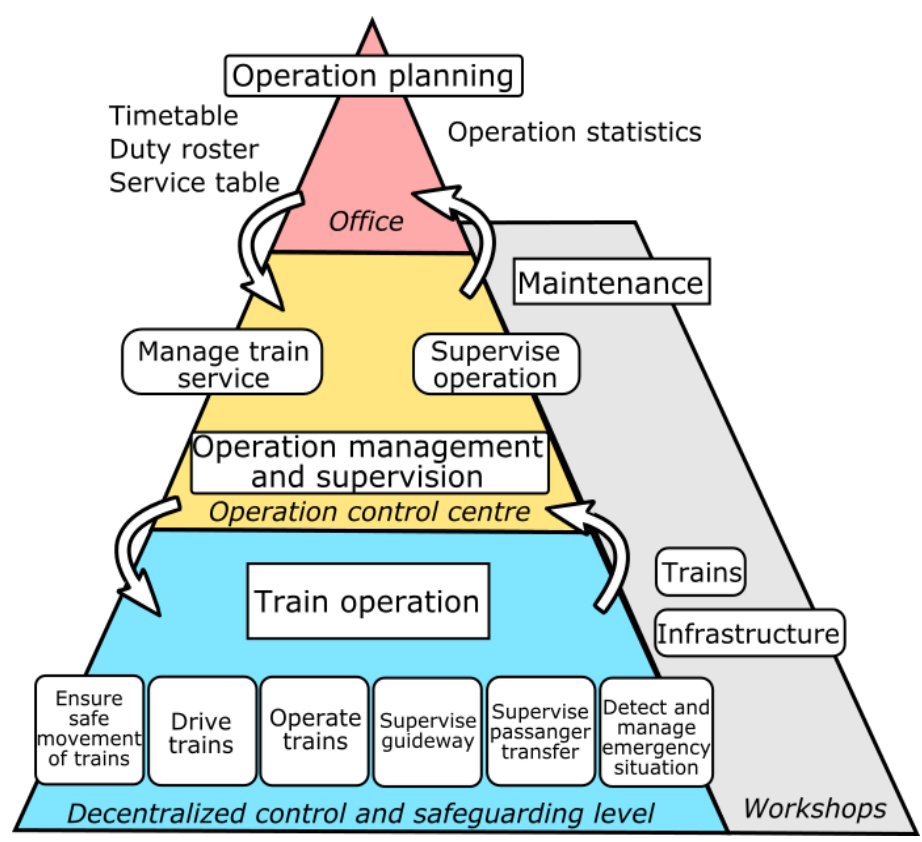

Fig. 1. Organization and operation structure of UGTMS [9] 


\subsection{System Architecture}

Critical points need to be identified, before we begin to build the security measures of the system. We used UGTMS architecture according [9] shown in Fig. 2 for this purpose. Fig. 2 represent the lower two levels of the pyramid shown in Fig. 1, i.e. the Operation management and supervision, and train operation. However, Fig. 2 shows also links from these two levels out the system, for example to operation planning or maintenance.

The cybernetic core of the UGTMS composes of three subsystems:

- Onboard Subsystem.

- Wayside Subsystem.

- Operation Control Subsystem.

Exchange of data and information is necessary to ensure among these three subsystems. Data Communication Subsystem secures the exchange of data and information. As it is discussed at introduction, a dedicated network of communication systems through the open radio space and public communications links are used for communication. Fig. 2 illustrates a big number of interfaces between cybernetic systems with different security level requirements. Interfaces are located both on the outer edge of UGTMS cyberspace (passenger information, operation planning, CCTV surveillance, etc.), as well as at inner space of the system itself (Data Communication Subsystem). Security gates are necessary to build on these interfaces to ensure the security level requirement.

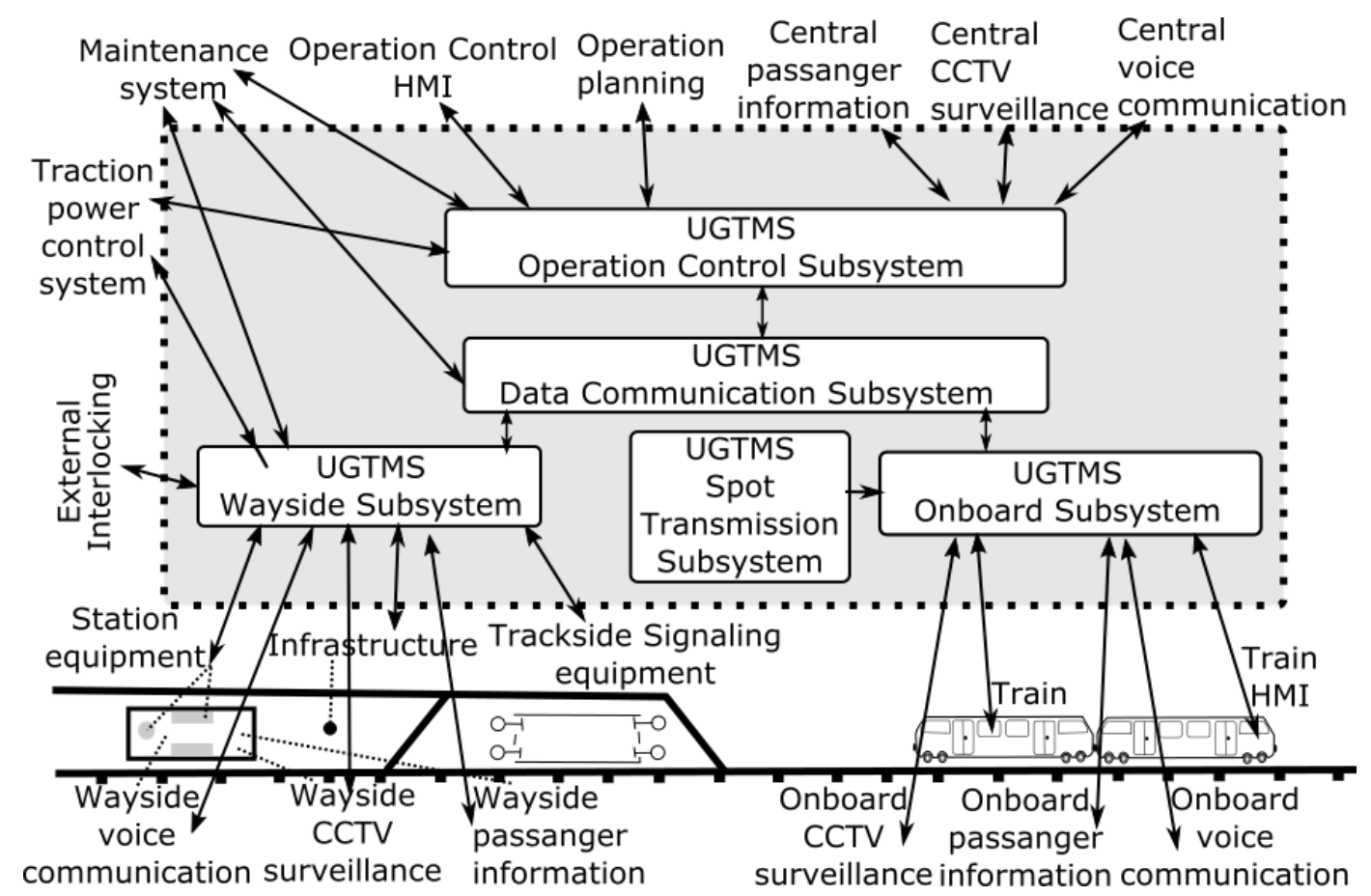

Fig. 2. The Urban guided transport management system architecture [9]

The number of security gates needs to be large, because we need to ensure safety of the Operation Control Subsystem as well as to guarantee the transmission path for each train and wayside elements. Security levels requirements need to be set up and ensured in view of the fact, that it is a CPS alongside. A cyber-attack on the CPS can lead to great material and human health damage and harm.

\subsection{Cyber-attacks at cyber-physical systems}

We live at a time when there are regular reports of cyber threats, whether associated with unknown invaders or technology manufacturers. Information security is often discussed in the context of these cases, but there is a little talk of possible impacts on the CPS. The disruption of information security, for example at the office level on Fig. 1, may lead to financial damages depending on the value of the infringed information. The disruption of the cyber security of the CPS as Operation Control Center, on the other hand, can lead to damage of both parts, the cybernetic as well as the physical part of the system. Losses on information, materials and human health and lives of CPS can be accompanied with losses on protected assets of neighborhood systems connected by links and flows to the CPS. Although, the CPS parts are at the bottom, from the point of view of the management levels, the requirements for their security levels are much greater. The critical infrastructure operators need to be convinced about this fact, as well as with industry 4.0, the heavy and chemical industry operators. 


\section{Multiple Independent Levels of Security}

Regards to present knowledge and experience on the MILS, we further concentrate attention to: its operation principles; its operation planes; and its physical realization.

\subsection{Operation principles of MILS}

The previous chapter describes the situation where we have interfaces between subsystems with different security level requirements in cyberspace. We can also talk about trustworthy and untrustworthy space. The Information flow between these spaces needs to be secured, and it is necessary to build security gates to prevent the compromising of a trusted subsystem. Types of security barriers are described for example in standard IEC / ISA 624432018 [8].

The Standard IEC / ISA 624432018 does not only describe the elemental safety barriers and procedures for control and autonomous systems in cyberspace but far more. It contains foremost the principles and requirements that the application of such barriers and procedures should meet, for example, in production networks of industry 4.0 or at the technical and operational level of critical infrastructure. One of the fundamental philosophies of standard IEC / ISA 62443 2018 is the application of the "Defense in Depth" principles. We build the multiple security barriers, when we apply defense in depth principles. Each one of security barriers then counts for the possibility of failure of the other barriers.

The principles inserted in the MILS approach [7] fully meet requirements of defense in depth strategy in the security area of information flow between trusted and untrusted parts of cyberspace. Principles of MILS approaches stand for the creation of multiple gateways and security procedures through which the information flow needs to pass, Fig. 3. Each gateway and each security procedure have their own resources (CPU, Hard drive, RAM, Ethernet, etc.). Disruption of one security barrier will not endanger the other barriers.

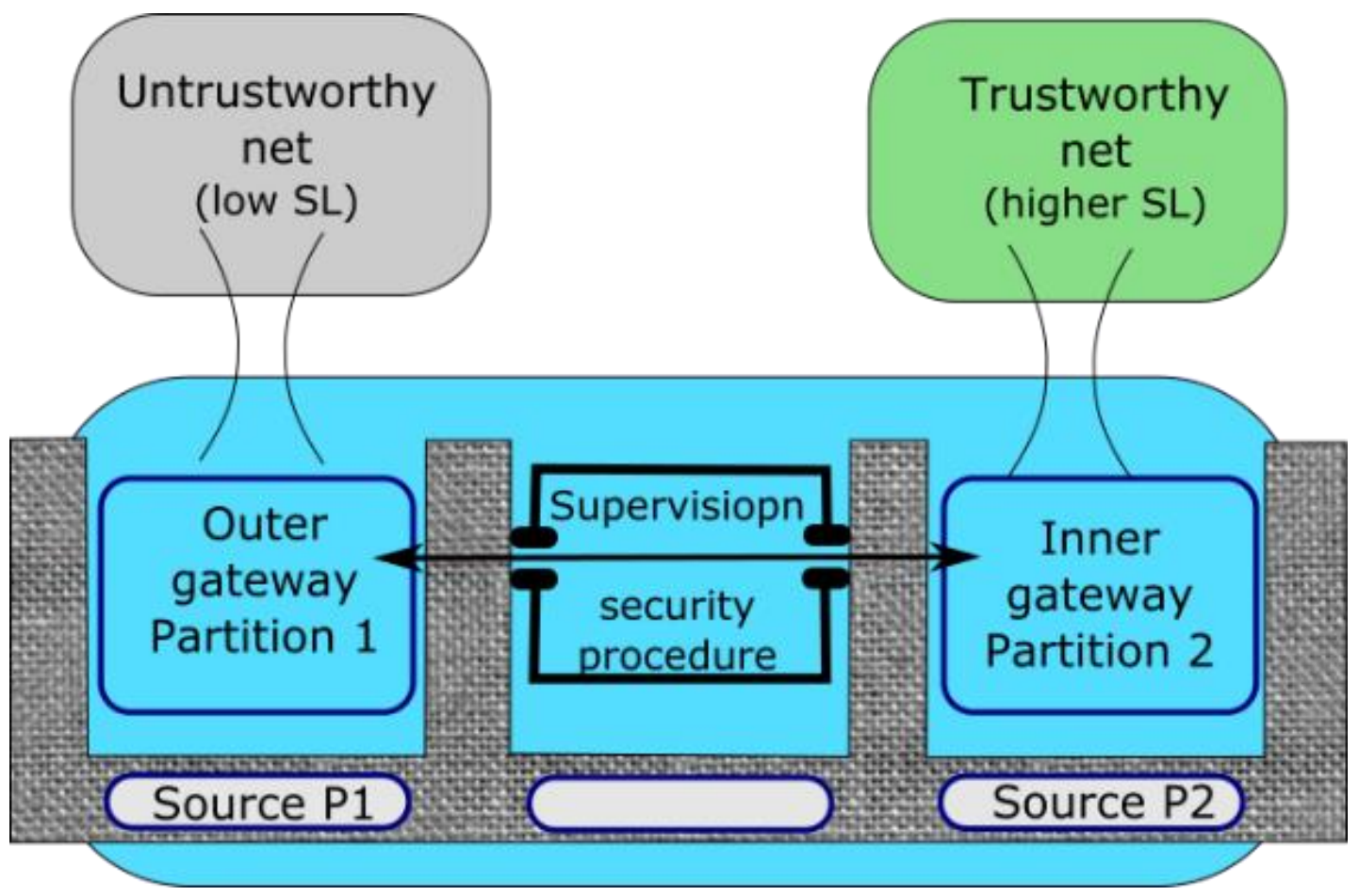

Fig. 3. Schematic representation of the interface between trusted and untrusted networks when applying MILS principles

\subsection{Operation planes of MILS}

The MILS Approach application assumes that security setting starts already at the hardware level. Independent operation of individual gates and procedures requires also security settings of system to be respected on all operation planes of MILS, Fig. 4. Following principles need to be comply with:

- The operating system may not randomly allocate sources, as in the case of conventional operating systems. It needs firmly to follow the configuration plane (such as PikeOS).

- The configuration plane or configuration file is the weakest point of the system and it needs to be protected accordingly (because affecting the all partitions).

- The robustness of safety procedures on the monitoring plane greatly influences the benefits of the MILS system. 


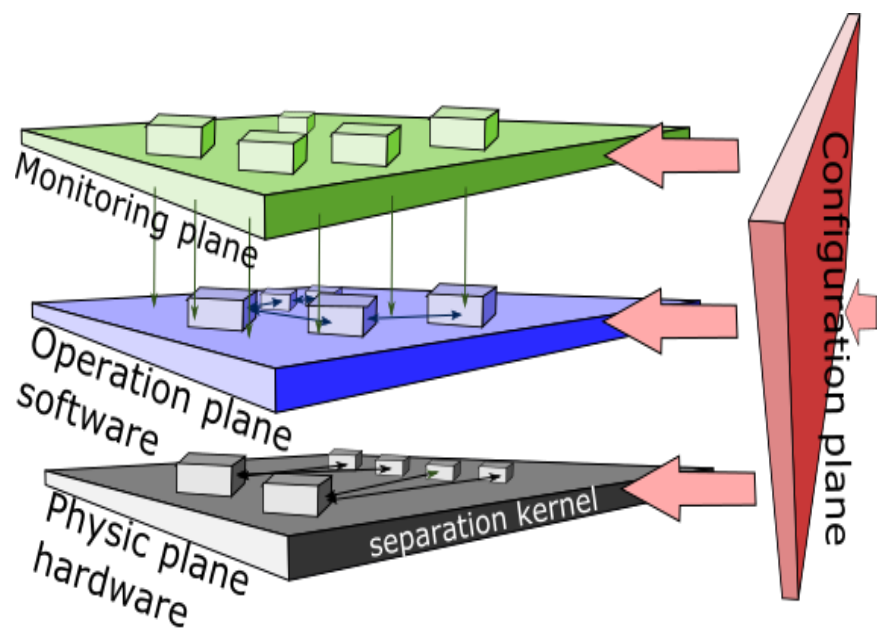

Fig. 4. Planes of MILS implementation, Physical plane (Hardware), Operation plane (Software), Monitoring plane (Security procedures) and Configuration plane (Configuration file) [1], [2]

An adaption plane is sometimes present in the planes of MILS implementation, Fig. 4. The adaption hold position on the right side to the configuration plane, which it affects. The way how to implement the dynamic adaptability in the MILS without threaten its security is the subject of an invention. For example, the projects CITADEL (2016) and CertMILS (2017) deal with it in the European space; see Chapter 4 for more details [1], [2].

\subsection{Physic realization of MILS}

Several ways how to implement the MILS principles are known. Way of fixed allocation of resources, such as an Ethernet connection or Hard disk space, are obvious. A question of fixed allocation of CPU is more complicated. It is of course possible to have own processor for each barrier. This is, however, a very impractical option. In practice, the MILS is implemented on a single processor. A processor can be either multi core or single core. Distribution of resources for multicore CPU logically suggests to assign each core to different partition. If we have single core processor or there are less cores than security barriers, "kernel separations" [23] can be performed and individual core partitions are assigned to individual interface partition.

The security level of individual barriers is also important for the functioning the whole system. The benefit of MILS approach is weak or negligible in the case of weak or negligible barriers. However, we will get overall MILS security level with combination of barriers with high security level that we would otherwise find difficult or impossible to achieve. Barriers should also be of different settings. The MILS principle also allows to combine technologies from multiple manufacturer for different partitions so that none of them have "keys" from the entire system. The system integrator is than only one, who has the access to whole system. We can then measure and compare barriers from individual manufacturer to get information about their behavior. However, integrator need to remember that the complexity of the system (the number and variety of barriers) increases demand for its operation and new threats can arise.

\section{Pilot Project}

We give example of introducing the MILS in the Praha subway.

\subsection{Metro / Subway}

The MILS Community addresses the development of the MILS approaches and its implementation into the protection of European infrastructures [15]. The MILS Community brings together the European technology companies and Academia, representatives of cyber security science from different areas. The MILS Community makes to use of various European projects and addresses through them the challenges that arise in the application and development of new technologies, compatibility with standards such as IEC / ISA 624432018 and pilot projects in areas like railways or smart grids. Projects CITADEL (2016) and CertMILS (2017) also deal with possibility of application at Praha Metro [1], [2].

The Praha Metro is the classic representative of UGTMS [9]. The Praha Metro does not reach the scale or intensity of transport of the largest European metropolis. However, the three lines transport 1.2 million people per day - 1.6 million journeys per day - 0.4 million transfer between lines [3]. These numbers document that Praha Metro is at least a critical regional infrastructure. The most occupied route $\mathrm{C}$ connects the largest Praha suburbs (middle class inhabitation) and the center of the city (offices and other workplaces) and its disturbance, such as falling the person into the railroad track, leads very fast to overflowing other transport infrastructure. 
The MILS protection is tested in the UGTMS Onboard Subsystem at the Praha Metro, at present, Fig. 2. In near future, every metro train will be equipped with the MILS protection. The transfer of information about position and other driving properties, as well as the remote control and communication with the operating center, should, therefore, be protected from cyber-attacks.

\subsection{Integration and adaption}

A concept of solution is not enough to solve technological problems, such as cyber-attacks in practice. A choice of suitable components (hardware and software), a way of their integration, certification, and in a dynamic environment such as cyberspace, a procedure of adaptability to new threats are also necessary. A diversification of the suppliers and manufacturers of individual components of the system can increase the security as well as the complexity of the security barrier system, as was mentioned above. We have three levels of access and responsibilities in the question of gate control, Fig. 5:

- Manufacturers of individual elements.

- The integrator.

- An operator / user.

All three levels have their own rules (standards), which they are managed by, and the supervisory authorities that oversee them. Manufacturers, the integrator and an operator have also access to different parts of the system.

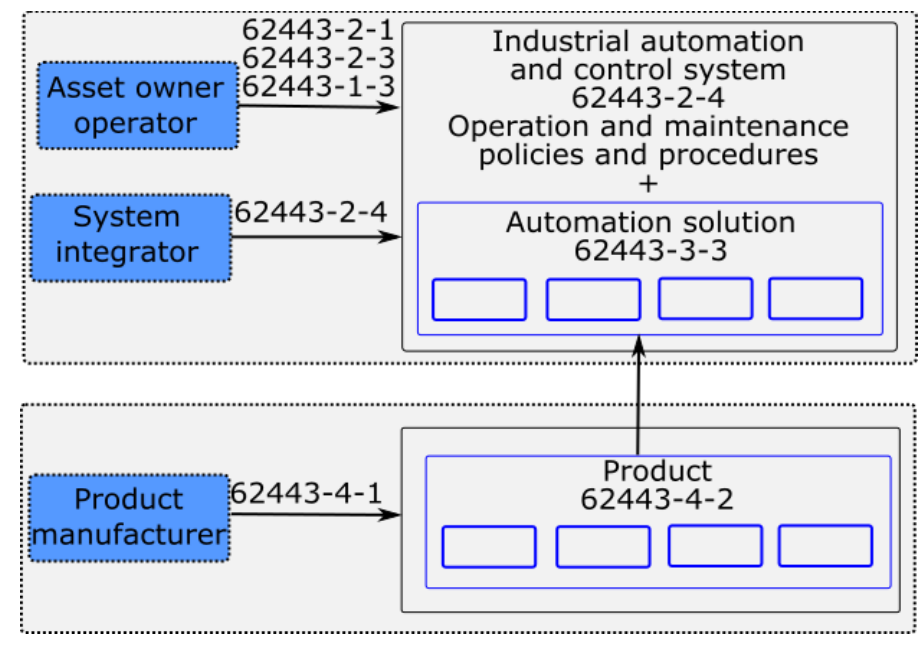

Fig. 5. Three Levels of Responsibility, Manufacturer, Integrator and Operator. Different parts of standard IEC/ISA 624432018 for different phase of application

The technological setup of MILS called "T-Composition" was designed for the needs of the Praha Metro and other pilot cities. T-Composition are described in deliverable 8.1 of projects [1], [2]. The verification of MILS T-Composition usability in the Metro Onboard Subsystem is one of the activities within these projects CITADEL (2016) and CertMILS (2017). The use of the technology is assumed at the interfaces between the Data Communication Subsystem and the Metro Operation Control Subsystem, the Metro Onboard Subsystem and the Metro Wayside Subsystem, Fig. 2.

The next step with that projects CITADEL 2016 and certMILS 2017 deal, is the certification. Certification in relation to adaptability (or adaptability in relation to certification) is the issue for a separate article. The manufacturer, integrator and operator need to follow the various standards for operation, depending on the area of their activities, e.g. the UGTMS operator follow IEC 622902018 standard. The standards do not create obligations only for them, but also create requirements for the previous segment of supply chain, Fig. 5.

The area of cyber security is covered by own standards. We write here mainly about a standard IEC/ISA 624432018. The standard IEC / ISA 624432018 is not legally binding at Europe, but it gives guidance, how to proceed or what to expect from previous segments of supply chain point of view of individual technological parts as well as from the point of view of the whole system integration. The cyber security of individual components can be also standardized with the Common Criteria (ISO/IEC 15408 1999) [10]. Both standards (IEC / ISA 624432018 and ISO/IEC 15408 1999) are considered in the European projects CITADEL (2016) and CertMILS (2017).

The possibility of reconfiguration based on operation requirements, adaptability, is one of the most important features of the system. Implementation of this quality in practice has considerable financial resources. Processes that can easily verify and implement these reconfigurations is necessary to prepare and apply. The solution of this issue is the technological setup of MILS called "I-composition", deliverable 8.1 of CITADEL 2016 and CertMILS 2017. Icomposition forms the certified foundation of the system. The I-composition are expanded with another attachments until the desired T-composition is achieved in Fig. 6. The project CertMILS 2017 deals with this issue. 


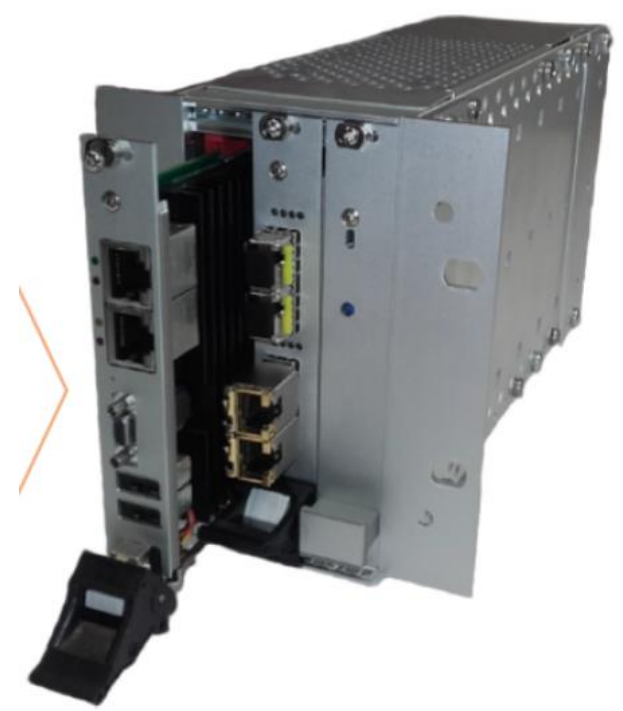

Fig. 6. T-composition box with card according to CITADEL (2016) and CertMILS (2017)

The system capability of adaptation has several levels. Projects CITADEL (2016) and CertMILS (2017) work now with three possible way of adaptability, fully self-adaptable system, semi self-adaptable system and manual-adaptable system:

- The system, which can evaluate situation, define the most optimal configuration, secure switch and accomplish certification without the human intervention, stand at the highest level of the dynamic self-configuration CITADEL 2016. The difficulty of fully self-adaptable system creation lies in maintaining the independence of individual security barriers and real-time certification.

- The semi self-adaptable system is easier to setup. The semi-dynamic system has several the "allowable states" of resource distribution [2]. All allowable states are verified and certified beforehand. The system can switch only between allowable states. Secure procedure of switching needs to be prepared.

- The manual-adaptable system is lest progressive from discussed ways of adaption, but it is also connected with lesser risk from unsupervised procedures. The manual-adaptable system uses the "I-composition" [1], [2]. Verified and certified I-composition has form of box with slot for cards, Fig. 6. The card can be easily removed, modified, and installed back to box. The box and cards together create T-composition.

\section{Future research \& plan}

Further research is planned to focus mainly on the application of the model of using the MILS platform in the data communication subsystem, which connects the individual UGTMS subsystems (Wayside subsystem, On-board subsystem and operation control subsystem) and the feedbacks.

\section{Conclusion}

The criticality of infrastructures as well as the vulnerability are increasing with increasing the dependence of human systems on infrastructures. The cybernetic infrastructure is one such area where new harmful phenomena are dynamically emerging. The security disturbance caused by unknown attacker, hardware manufacturer or software developer has a great media attention today, although these phenomena have been present for a long time. The protection of information and communications only at the information level with the help of the software is not sufficient. The hardware measure at the cybernetic security level is also necessary. The CPSs are particularly critical from the point of view of cyber-attack because they are associated with the physical world and physical impacts.

The concept of MILS has higher overall security level than individual barriers. The increments of infrastructure criticality and arise of new harmful cybernetic phenomena demand application of advanced security procedures. The European Critical Infrastructure operators, therefore, implement the MILS protection in rising number. The Praha Metro is one of operation, where the utilization of MILS principles is tested.

\section{Acknowledgement}

The results published in the article were created with the support of the European projects "CITADEL" ID: 700665, "CertMILS" ID: 731456 and "RIRIZIBE" CZ.02.2.69 / 0.0 / 0.0 / 16-018 / 0002649 and project SSZP 4771675/2019 and project SSZP 4771675/2019. 


\section{References}

[1] CertMILS (2017). Compositional security certification for medium- to high-assurance COTS-based systems in environments with emerging threats. EU, Horizont 2020, no 731456.

[2] CITADEL (2016). Critical Infrastructure Protection using Adaptive MILS. EU, Horizont 2020, no. 700665.

[3] DPP. (2015, 11. December). Pražské metro v den přepravního průzkumu přepravilo 1272143 cestujících. DPP. Praha. Available from: http://www.dpp.cz

[4] Dunn, M. \& Wiegert, I. (2004). Critical Information Infrastructure Protection. International IIP Handbook. 405p. ETH. Zurich.

[5] EN 50126-1 (1999). Railway applications - The specification and demonstration of Reliability, Availability, Maintainability and Safety (RAMS). CENELEC, Brussels.

[6] EU. (2005, 17. November) Green Paper on European Programm for Critical Infrastructure Protection. EU $\operatorname{COM}(2005)$ 576. Brussel.

[7] Harrison, W. S. (2005). The MILS Architecture for a Secure Global Information Grid. The Cross Talk Journal of Defense Software Engineering.

[8] IEC / ISA 62443. (2018). Security for industrial automation and control systems. International Electrotechnical Commission / International Society of Automation. IEC and ISA, draft.

[9] IEC 62290-3 (2018). Railway applications - Urban guided transport management and command/control systems. IEC, draft.

[10] ISO / IEC 15408 (1999). Common Criteria for Information Technology Security Evaluation. ISO and IEC. Available from: https://www.commoncriteriaportal.org/

[11] KRÁliKOVÁ, R. \& PAULIKOVÁ, A. (2008). Modelling and diagnosing of mechanical engineering lifecycle production process. - In: Chemické listy. Vol. 102 (S), no. Symposia, p. 399-401. ISSN: 0009-2770

[12] Kralikova, R.; Sokolova, H.; Wessely, E. \& Polak, J. (2013). Approaches to assessment of hot environment. DAAAM International Scientific Book 2013. chapter 14. Vienna. DAAAM International. pp. 317-328. ISBN: 9783-901509-94-0

[13] Lukas, L. \& Hromada, M. (2011). Risk analysis in context of kritical infrastructure protection. - Annals of DAAAM for 2011 \& Proceedings of the 22nd International DAAAM Symposium, Volume 22, No. 1, ISSN: 1726-9679, Katalinic, B. [ed.] Published by DAAAM International, Vienna

[14] Majernik, M.; Kupec, V.; Majernik, S. \& Zatrochova, M. (2011). Finančné riadenie podniku. - Bratislava: STATIS, ISBN: 978-80-85659-67-2

[15] MILS Community (2019, January). MILS Community. Available from: http://mils.community

[16] Moteff, J.; Copeland, C. \& Fischer, J. (2003). Critical Infrastructures: What Makes an Infrastructure Critical? - CRS Web, Report for Congress, Order Code RL31556.

[17] Necesal, L.; Lukas, L. \& Jasek, R. (2011). Measures for critical infrastructure protection in the Czech republic. Annals of DAAAM for 2011 \& Proceedings of the 22nd International DAAAM Symposium, Volume 22, No. 1, ISSN: 1726-9679, Katalinic, B. [ed.] Published by DAAAM International, Vienna, pp. 0843-0844

[18] Peerenboom, J. (2001). Infrastructure Interdependencies: Overview of Concepts and Terminology. - Argonne National Laboratory, National Science Foundation Workshop, Argonne.

[19] Prochazkova, D. (2014). Challenges connected with critical infrastructure safety. - Lambert Academic Publishing ISBN: 978-3-659-54930-4. 218p.

[20] Procházková, D. \& Rusko, M. (2017). Relation between human system safety management and environmental management. - In Journal of Environmental Protection, Safety, Education and Management. Vol. 5, No. 9, ISSN: 1339-5270

[21] Prochazkova, D.; Prochazka, J.; Rusko, M.; Mikulova, M. \& Ilko, J. (2017). Model for critical infrastructure safety management. In Annals of DAAAM for 2017, Volume 28, No.1. The 28th DAAAM International Symposium. Zadar, Croatia. Vienna : DAAAM International, ISSN 2304-1382. ISBN: 978-3-902734-14-3. DOI: 10.2507/28th.daaam.proceedings.085.

[22] Procházková,, D.; Wessely, E.; Rusko, M. \& Kralikova, R. (2011). Human System Safety Management and Environmental Management Relation. In DAAAM International Scientific Book 2011. pp. 103-118. ISSN: 17269687; DOI: 10.2507/daaam.scibook.2011.09

[23] Rushby, J. (1981). The Design and Verification of Secure Systems. - Eighth ACM Symposium on Operating System Principles, pp. 12-21, Asilomar. (ACM Operating Systems Review, Vol. 15, No. 5). 